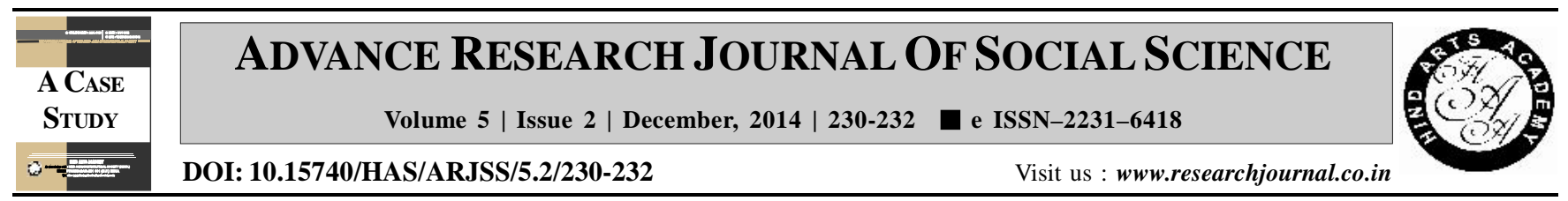

\title{
Extent of participation of couples especially husbands in household activities
}

Jiju N. Vyas and Bhawana Asnani*

Polytechnic in Home Science (J.A.U.), AMRELI (GUJARAT) INDIA

(Email: bhawana_asnani@yahoo.com)

\section{ARTICLE INFO :}

Received Accepted

: 10.09 .2014

: 21.11 .2014

\section{KEY WORDS :}

Couples, Husbands, Wives, Extent of participation, Household activities

\section{HOW TO CITE THIS ARTICLE :}

Vyas, Jiju N. and Asnani, Bhawana (2014). Extent of participation of couples especially husbands in household activities. Adv. Res. J. Soc. Sci., 5 (2): 230-232.

*Author for correspondence

\begin{abstract}
Women play a dynamic role in their home activities, as wife, as mother who is responsible for development of the children and as homemaker, in charge of the operation of their homes. In recent times, with the increase in educational facilities and wide spread change in resource available, women have gradually started taking employment outside the home. They have now an added major role that of as a wage earner. The research objective was to explore the extent of participation by young and old spouses in selected household activities. Survey and interview schedule was used on the selected couples of Mehsana District of Gujarat. The result concluded that young couple's participation was more than old couple; the deference was not waste but it would be noted that young generation took more interest in domestic responsibilities and managed their challenge efficiently.
\end{abstract}

